American Journal of Pharmaceutical Education 2020; 84 (3) Article 6972.

\title{
BRIEF
}

\section{Pharmacy Students Teaching Prescription Writing and Nonprescription Product Selection to Medical Students}

\author{
Sheila M. Allen, PharmD, Marlowe Djuric Kachlic, PharmD, Louise Parent-Stevens, PharmD \\ University of Illinois at Chicago College of Pharmacy, Chicago, Illinois
}

Submitted January 22, 2018; accepted August 8, 2019; published March 2020.

Objective. To measure the impact of an interprofessional education intervention in which pharmacy students provided education to medical students.

Methods. In a required workshop, fourth-year pharmacy students taught second-year medical students the basics of prescription writing. In a subsequent selective education session, the pharmacy students led a case-based discussion on nonprescription drug use for third-year medical students on their family medicine rotation. The pharmacy students were surveyed in regards to confidence in teaching abilities before and after the prescription writing workshop and the medical students were surveyed in regards to confidence with activity and teaching effectivess prior to and after the completion of the workshop or selective.

Results. At the end of the workshop, second-year medical students were more confident in their abilities to write prescriptions and fourth-year pharmacy students were more confident in their ability to teach prescription writing. Based on survey responses, the second-year medical students and fourthyear pharmacy students were confident in the learning environment effectiveness throughout the activity. After participating in the selective education session, third-year medical students were more confident in their ability to access resources on nonprescription drugs and in making recommendations to and counseling patients regarding nonprescription drug use.

Conclusion. The perception is that pharmacy students can be effective interprofessional educators for medical students on key aspects of the medical curriculum.

Keywords: interprofessional, IPE, students, teachers, medical

\section{INTRODUCTION}

Interprofessional education (IPE) is becoming increasingly important as the US healthcare system moves towards more team-based patient care. As such, the 2003 Institute of Medicine's report, Health Professions Education: A Bridge to Quality, spoke about a "new vision" for health professions education, recommending work in interdisciplinary teams as a core competency for health professions education. ${ }^{1}$ In 2013, the Accreditation Council for Pharmacy Education (ACPE) standards required the incorporation of IPE into Doctor of Pharmacy (PharmD) degree curricula. ${ }^{2}$ Similarly, in 2014, the Liaison Committee for Medical Education (LCME) implemented a new medical school accreditation standard addressing the role of IPE in support of team-based care. ${ }^{3}$ These requirements for IPE within curricula have

Corresponding Author: Sheila M. Allen, University of Illinois at Chicago College of Pharmacy, $833 \mathrm{~S}$ Wood St., Ste. 164/MC 886, Chicago, IL 60612. Tel: 312-355-0371. E-mail: sallen7@uic.edu extended across health education disciplines as outcomes suggest that IPE may positively impact patient care outcomes. ${ }^{4}$

Health professions students gain a better understanding of professional roles through their participation in IPE activities. ${ }^{5,6}$ However, published literature related to IPE activities involving pharmacy students to date has typically centered on models where the faculty member or clinician from a given health discipline is serving as the teacher for an interprofessional activity or an interprofessional team of health care students are serving as teachers to the lay public. Thus, the specific model of the pharmacy student serving as the primary teacher within an individual IPE activity has not been documented.

At the University of Illinois at Chicago College of Pharmacy, faculty members have engaged with faculty members in the college of medicine in regards to two distinct initiatives where pharmacy students serve as the primary teacher within an IPE activity: prescription writing and nonprescription product selection. We hypothesized that using pharmacy students as teachers 


\section{American Journal of Pharmaceutical Education 2020; 84 (3) Article 6972.}

within these IPE initiatives would be an effective teaching endeavor and improve both the pharmacy and medical students' confidence in the pharmacy students' teaching abilities. Additionally, we hypothesized that this teaching model would also improve medical students' receptiveness to learning from other health professions students as well as pharmacy students' receptiveness to teaching other health professions students.

\section{METHODS}

Two educational endeavors were undertaken. The study protocols for both interventions were approved by the University of Illinois at Chicago Institutional Review Board. For the first activity, second-year medical students participated in a prescription writing workshop, which is a component of the required Essentials of Clinical Medicine course. The workshop was taught by fourth-year pharmacy students who had experience working in a community pharmacy or had completed their community advanced pharmacy practice experience (APPE). The pharmacy students were recruited through an email sent to the class listserv one month prior to the session. Students who volunteered were given the facilitator materials (the exercises with answers as well as the plenary session slides) to review the week prior to the workshop. In the hour prior to the workshop, faculty members reviewed the activities with the pharmacy students involved, including answering their questions and providing tips on delivering the information. The 3.5-hour workshop began with a pharmacy faculty member providing a one-hour plenary session on the critical points of prescription writing to 200 second-year medical students. Materials presented in the plenary session as well as the exercises the medical students completed during the workshop were developed by a group of fourth-year pharmacy students on an academic APPE and one of the faculty members coordinating the workshop. After the plenary session, the medical student were broken up into their usual 12- to 15-person work groups and assigned to separate meeting rooms, where the workshop continued. Two pharmacy students led the medical students in each of the work groups through several exercises illustrating the finer points of prescription writing, such as writing sigs with complicated directions, finding errors in completed prescriptions, writing prescriptions for devices and supplies, and counseling a patient on a new medication. At the end of the semester, all of the second-year medical students completed an objective structured clinical examination (OSCE) where one of the exercises included writing four prescriptions of varied complexity based on different scenarios covered in the workshop.
One week prior to the workshop, a survey (Qualtrics, Provo, UT) was sent to all 200 medical students to assess the following, using a Likert scale: confidence in writing different types of prescriptions, effectiveness of the pharmacy students' teaching, and perception of the role of the pharmacist on the healthcare team. At the conclusion of the workshop, another survey was sent out that asked the same questions as the pre-workshop survey. In addition, the survey asked the medical students to rate the helpfulness of the workshop, as well as provide any comments. The post-workshop survey was open for one week after the workshop.

The day prior to the workshop, the 22 pharmacy students were surveyed about their confidence in facilitating the small-group session on prescription writing and asked to assess how receptive the medical students would be to their teaching. The pre-workshop survey sent to fourth-year pharmacy students also collected information on work history as well as prior experience facilitating a workshop, recitation, or laboratory session. After the workshop, the pharmacy students were asked to complete a post-workshop survey that asked the same questions regarding confidence in their knowledge of the material and perceived receptiveness of the medical students to their teaching, and asked them to provide any comments about the workshop. This survey was also open for one week after the workshop.

The second activity occurred during the required family medicine rotation in the third year of the medical school curriculum. A subset of third-year medical students on this rotation chose to participate in a two-session selective on nonprescription medications. Prior to the first session, all medical students enrolled in the workshop received a slide set created by pharmacist faculty members and students that discussed common nonprescription medications for pain and fever, cough, cold and allergies, and gastrointestinal disorders, as well as selected vitamins and minerals. The first two-hour session involved a casebased discussion of these topics led by a group of fourthyear student pharmacists. For the second two-hour session, each participating medical student developed, answered, and presented a self-identified, case-based clinical question from their rotation related to the use of a nonprescription medication, or vitamin, mineral, or herbal medication.

The participating pharmacy students were completing either an academic or ambulatory care APPE with one of the two pharmacist faculty members who developed the selective at the time of the study. One to two weeks prior to the first session, these students updated the pre-workshop slide set and developed cases for use in the first selective session. These were then 


\section{American Journal of Pharmaceutical Education 2020; 84 (3) Article 6972.}

reviewed by the pharmacist faculty member who provided feedback and guidance to the students in making any modifications. Discussion during the second session was facilitated by the participating fourth-year pharmacy students.

Prior to the first session of the selective, a survey (Qualtrics, Provo, UT) was sent to all of the third-year medical students completing the Family Medicine clerkship (approximately 25 students every six weeks) with items regarding their knowledge and confidence, using a Likert scale, in counseling patients about and recommending nonprescription medications and herbal products. Medical students who participated in the selective were surveyed after the session about their confidence on recommending and counseling patients on nonprescription medications and herbal products. Preand post-survey results from both activities were compared using an independent two-tailed $t$ test to determine significance, which was defined as $p<.05$.

\section{RESULTS}

Twenty of the 22 pharmacy student volunteers completed the survey administered prior to the prescription writing workshop. All 22 volunteers completed the post-workshop survey. The pharmacy students' baseline work experience and small group facilitation experience are presented in Table 1. The pharmacy students' responses regarding confidence in their ability to teach the material presented in the workshop to the second-year medical students as well as the perceived receptivity of the medical students to their teaching are presented in Table 2.

One hundred forty-three of the 200 second-year medical students completed the pre-workshop survey, and 103 of 200 completed the post-workshop survey. The medical students' ratings regarding their confidence in the material presented during the workshop as well as their confidence in the pharmacy students' ability to teach prescription writing to them are depicted in Table 3 . The medical students saw pharmacists as having an important or very important role in the healthcare team both before

Table 1. Community Pharmacy Work History and Teaching Experience of Fourth-Year Pharmacy Students Who Served as Instructors in a Prescription Writing Workshop for SecondYear Medical Students $(\mathrm{N}=20)$

\begin{tabular}{lc}
\hline Survey Item & Response, $\%$ \\
\hline Worked as technician in community pharmacy & 85 \\
Technician for $\geq 3$ years & 70 \\
Facilitated a small group interactive session & 75 \\
Facilitated $\geq 5$ times & 40 \\
\hline
\end{tabular}

and after the workshop (93\% and 98\%, respectively). After the workshop, 93 (90\%) of the medical students felt that the workshop would be "helpful" or "extremely helpful" to them as they moved forward in their clinical experiences.

All second-year medical students passed the prescription writing portion of the OSCE conducted at the end of the semester. The College of Pharmacy faculty members that coordinated the workshop also graded the prescription writing OSCE and created a list of common errors made, which were given to the medical students at the next IPE workshop. Commonly made errors included inappropriate use of National Provider Identifier (NPI) and Drug Enforcement Administration (DEA) numbers; incorrect use of "may not substitute"; and failure to include all parts of a sig.

Prior to the OTC Drugs Selective, 68 third-year medical students responded to the pre-selective survey. Of those, 36 (54\%) participated in the selective. Twentyfive of the medical students who participated in the selective completed the post-selective survey. After participation in the selective, the medical students were significantly more likely to indicate familiarity with online resources for looking up nonprescription medications, feel more confident making recommendations for patients on non-prescription medications, and feel more confident about counseling patients on their use of nonprescription medications (Table 4). The medical students who participated in the selective were not significantly more likely to ask patients about their use of non-prescription medications than medical students who did not participate in the selective.

\section{DISCUSSION}

Overall, both teaching initiatives were successfully led by fourth-year pharmacy students. Specific to the Prescription Writing Workshop, second-year medical students were more confident in their prescription writing abilities after participating in the pharmacy student-led workshop. Additionally, the pharmacy students were more confident in their knowledge of the material they presented after teaching the workshop. Both the secondyear medical students and the fourth-year pharmacy students demonstrated a receptiveness to an interprofessional learning environment. Within the OTC Drugs Selective, third-year medical students showed improved confidence in their knowledge of and comfort with recommending nonprescription medications, as well as in their ability to access resources to find information on nonprescription medications. Within both of these teaching initiatives, the confidence of the teachers (pharmacy students) and the learners (second- and third-year 


\section{American Journal of Pharmaceutical Education 2020; 84 (3) Article 6972.}

Table 2. Fourth-Year Pharmacy Students Who Were Confident or Extremely Confident Teaching Prescription Writing to SecondYear Medical Students as Part of an Interprofessional Workshop

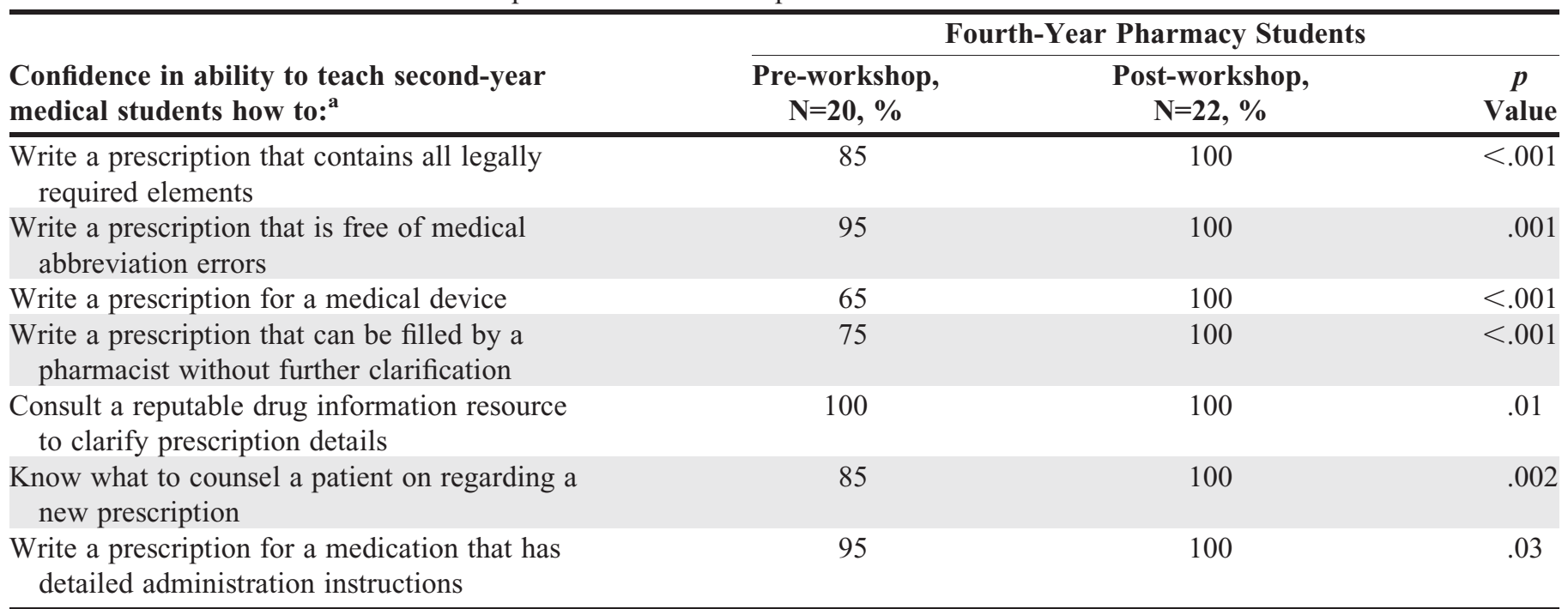

${ }^{a}$ Scale for this question was: not confident at all, somewhat confident, confident, extremely confident

medical students) in their abilities related to the material presented (prescription writing and nonprescription product selection) improved.

There are some limitations to consider in the interpretation of these outcomes. First, because our college of pharmacy and college of medicine are part of a health campus, the perception of pharmacists as part of the health care team might be more favorable than on a campus that does not have several health science programs located close together. Second, because the surveys were administered immediately after the activities were done, we do not know how the interactions affect pharmacists' and physicians' long-term perceptions of interprofessional relationships. Future research in this area might involve a survey to examine if these improved interprofessional attitudes continue into practice. While we used fourth-year pharmacy students with community work experience for the prescription writing workshop, the students had varying amounts of experience, though all had experience beyond just IPPEs. Also, the plenary session was taught by a college of pharmacy faculty member rather than a student. In future iterations of this

Table 3. Second-Year Medical Students Who Were Confident or Extremely Confident in Prescription Writing

\begin{tabular}{lccc}
\hline & $\begin{array}{c}\text { M2 Respondents } \\
\text { Pre-workshop N=143, \% }\end{array}$ & $\begin{array}{c}\text { M2 Respondents } \\
\text { Post-workshop N=103, \% }\end{array}$ & $\boldsymbol{p}$ Value \\
\hline $\begin{array}{l}\text { M2 confidence in ability to: }{ }^{\text {a }} \\
\begin{array}{l}\text { Write a prescription that contains all legally } \\
\text { required elements }\end{array}\end{array}$ & 6 & 64 & $<.001$ \\
$\begin{array}{l}\text { Write a prescription that is free of medical } \\
\text { abbreviation errors }\end{array}$ & 13 & 63 & $<.001$ \\
$\begin{array}{l}\text { Write a prescription for a medical device } \\
\begin{array}{l}\text { Write a prescription that can be filled by a } \\
\text { pharmacist without further clarification }\end{array}\end{array}$ & 3 & 43 & $<.001$ \\
$\begin{array}{l}\text { Consult a reputable drug information resource } \\
\text { to clarify prescription details }\end{array}$ & 8 & 63 & $<.001$ \\
$\begin{array}{l}\text { Know what to counsel a patient on regarding a } \\
\text { new prescription }\end{array}$ & 19 & 64 & $<.001$ \\
$\begin{array}{l}\text { Write a prescription for a medication that has } \\
\text { detailed administration instructions }\end{array}$ & 75 & 54 & $<.001$ \\
\hline Sct
\end{tabular}

${ }^{a}$ Scale for this question was: Not confident at all, Somewhat confident, Confident, Extremely Confident P4=fourth year student pharmacist; M2 $=$ second year medical student 


\section{American Journal of Pharmaceutical Education 2020; 84 (3) Article 6972.}

Table 4. Third-Year Medical Students Who Often or Always Ask, Recommend, and Can Counsel on OTC Medications

\begin{tabular}{|c|c|c|c|}
\hline & $\begin{array}{c}\text { M3 Respondents } \\
\text { Pre-Survey } \mathrm{N}=68, \%\end{array}$ & $\begin{array}{c}\text { M3 Respondents } \\
\text { Post-Survey } \mathrm{N}=\mathbf{2 5}, \%\end{array}$ & $p$ value \\
\hline $\begin{array}{l}\text { When interviewing patients, I ask about their } \\
\text { use of OTC medications }{ }^{\text {a }}\end{array}$ & 68 & 76 & .20 \\
\hline $\begin{array}{l}\text { I am familiar with online resources for looking } \\
\text { up OTC medications } b\end{array}$ & 47 & 96 & $<.001$ \\
\hline $\begin{array}{l}\text { When clinically appropriate, I feel confident } \\
\text { making recommendations about OTC } \\
\text { medications for patients } b\end{array}$ & 52 & 96 & $<.001$ \\
\hline $\begin{array}{l}\text { I feel confident counselling a patient on the use } \\
\text { of OTC medications }\end{array}$ & 52 & 80 & $<.001$ \\
\hline
\end{tabular}

workshop, APPE students could deliver the introductory session. A limitation of the OTC Drugs Selective was that we surveyed all medical students enrolled in the family medicine clerkship prior to the class, but then only surveyed the students who participated in the selective after the class. Because students who chose to complete the selective might have had some bias toward the topic (either higher confidence or lower confidence) to begin with, in the future we should provide the post-selection survey to all students so we can compare their responses. Additionally, comparing the two groups' responses before and after the selective might not illustrate the difference because the sizes of the groups were different. Finally, not all pharmacy or medical students participated in these activities.

Having a fourth-year pharmacy student take on the role of teacher is not unique. Many colleges of pharmacy use senior students in the training of junior students in both the classroom and experiential environments with favorable outcomes. Using fourth-year pharmacy students as teachers within IPE activities is a natural progression in their development as healthcare professionals. Our study has shown that fourth-year students serving as teachers within IPE activities has a favorable impact on students' confidence in their abilities and their perception of their role within the healthcare team.

The successful IPE initiatives described here have opened up opportunities for our pharmacy students to teach medical students in other areas, including administering immunizations, using inhalers, using diabetes injectables, and conducting glucose testing. Additionally, we are exploring having fourth-year pharmacy students teach dental students how to write prescriptions and provide immunizations. We hope that the expansion of these IPE initiatives will provide more pharmacy students the opportunity to participate and benefit professionally from these teaching experiences.

\section{CONCLUSION}

Using fourth-year pharmacy students as teachers was effective in terms of instructing second- and third-year medical students various practice-related skills, while improving both the medical and pharmacy students' confidence in their professional abilities. This study also found a receptiveness among students involved in these initiatives to participate in an interprofessional learning environment.

\section{REFERENCES}

1. National Research Council. Health Professions Education: A Bridge to Quality. Washington, DC: The National Academies Press, 2003.

2. Liaison Committee on Medical Education. Functions and Structure of a Medical School: Standards for Accreditation of Medical Education Programs Leading to the MD Degree; 2016. https://med.virginia.edu/ume-curriculum/wp-content/uploads/sites/ 216/2016/07/2017-18_Functions-and-Structure_2016-03-24.pdf. Accessed March 5, 2020.

3. Accreditation Council for Pharmacy Education. Accreditation Standards and Key Elements for the Professional Program in Pharmacy Leading to the Doctor of Pharmacy Degree ("Standards 2016"). Published February 2015. https://www.acpe-accredit.org/pdf/ Standards2016FINAL.pdf. Accessed March 5, 2020.

4. Reeves S, Perrier L, Goldman J, Freeth D, Zwarenstein M. Interprofessional education: effects on professional practice and healthcare outcomes (update). Cochrane Database Syst Rev. 2013;3. 5. Smith K, Scott D, Barner J, et al. Interprofessional education in six US colleges of pharmacy. Am J Pharm Educ. 2009;73(4):Article 61. 6. Jones K, Blumenthal D, Burke J, et al. Interprofessional education in introductory pharmacy practice experiences at US colleges and schools of pharmacy. Am J Pharm Educ. 2012;76(5):Article 80. 